\title{
Sustainable management of different valley ecosystems
}

\author{
Andrzej Brandyk ${ }^{1,}{ }^{*}$, Grzegorz Majewski ${ }^{1}$, Marcin Krukowski ${ }^{1}$, and Anna Baryła ${ }^{1}$ \\ ${ }^{1}$ Warsaw University of Life Sciences, Faculty of Civil and Environmental Engineering, \\ 159 Nowoursynowska St., 02-776 Warsaw, Poland
}

\begin{abstract}
Development and conservation of valley ecosystems has been an important issue for a long time, with respect to extensive, interdisciplinary research problems, offered ecosystem services and wide public interest. It has been as yet controversial, which indicators would describe the achievement of particular environmental status by those ecosystems, since they tend to be rather complex, showing fragile equilibrium and high vulnerability. With the use of hydrological modelling and proper criteria we demonstrated possibilities to balance well the concern for managers to control features regarding ecosystem health. It was evident during different hydroperiods, that ground water inflow conditions, influenced by investments into hydraulic structures functioning, arise as driving factor for environmental and ecological disturbance.
\end{abstract}

\section{Introduction}

River valleys are considered to contain numerous, valuable ecosystems, that are often subject to many threats all over the world. On one hand, natural changes of environmental processes are thought to be the cause of their disturbance, however, human-induced transformation is stressed extensively. Wetland habitats, in particular, have become unique but also vulnerable components of river valleys, that have already been given certain attention $[1,2,3]$. Not only their fate depends on prevailing land management influence and the intensity of natural resources exploitation. Natural, intact river valleys are nowadays scarce, since the majority of them contains traces of human impact on environmental reserves. Fortunately, their utilization ceased or was abandoned on some areas, in particular in Poland [4], becoming favourable to protection either successful restoration of selected landscape components (e.g. soil cover, plant communities, water bodies).

In the contemporary times, environmental management and protection plans have been refined, searching for proper tools to better control natural resources use. Their exploitation should not cause disturbance to an ecosystem, so much that the capacities and the production potential are lost for the sake of the future [4]. An urgent need to acknowledge human requirements, while at the same time to sustain the ability of natural system to provide the base of natural resources was finally formulated as sustainable development. It should not overlook the integrity and stability of the environment while satisfying peoples'

${ }^{*}$ Corresponding author: andrzej brandyk@,sggw.pl 
needs. Water storage and its spatiotemporal changes have caught special attention here, as basis for a wise river valley management $[4,5,6]$. At the same time, the search for reliable indicators of sustainable use of water resources was started. For this reason, the research herein was focused on hydrologic response of valley systems to current management practices. We omitted more complex and broader approaches to the maintenance of biological resources, showing mainly the development of ground water table. We hypothesized that the functioning of hydraulic structures helps managers to sustain water retention of the saturated zone of a valley ecosystem but with a marked decline of groundwater tables.

\section{Material and methods}

We based our research on two small valley areas in Poland. The first one is the Southern Całowanie Peatland, of 588,8 ha which has already been under protection as habitat for endangered wetland species for about 10 years. It is located $35 \mathrm{~km}$ south of the capital city of Warsaw (Fig. 1.), and constitutes only part of a large wetland complex that covers a wide extent of the Valley of the Vistula River. It forms a vast and interrelated system, containing valuable landscape components such as transitional bogs and single-swath meadows- the biodiversity of which strongly depends of the operation of the drainage-irrigation system (Fig. 2.). Still, the presence of wetland plant species there suggests that the drainage did not cause their considerable deterioration over last decades [7].

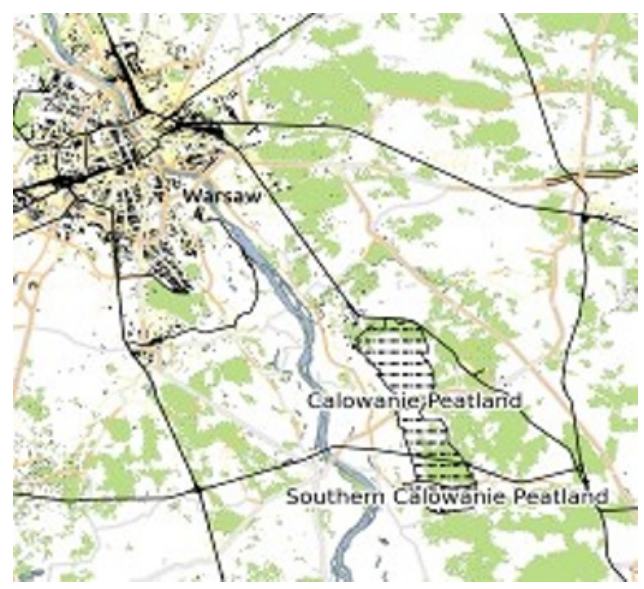

Fig. 1. Location of the first research area- Southern Całowanie Peatland.

One of the most important hydrologic features of that system is the underlying, thick $10 \mathrm{~m}$, sandy aquifer of a high permeability from the viewpoint of sustainable ground water resources management and overall ecosystem health. The aquifer is thought to contribute to upwelling of groundwater within a fragile wetland, and for this reason requires suitable maintenance. 


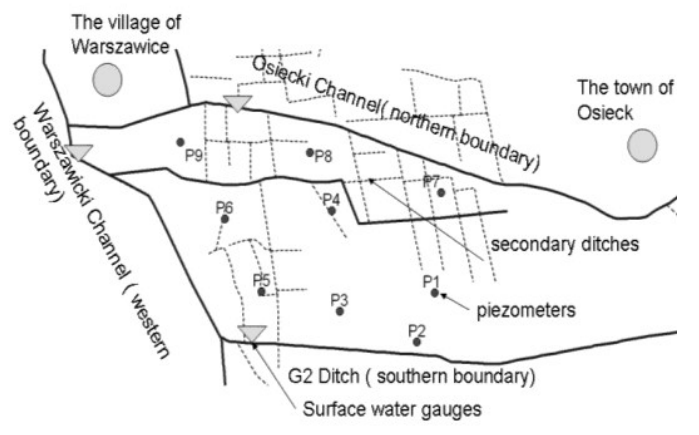

Fig. 2. Drainage -irrigation system of the first research area.

The second research area of 120 ha is located $20 \mathrm{~km}$ to the west of the city of Bydgoszcz in the Valley of the Notec River- one of the biggest rivers in that part of Poland, attributable to a number of economic functions (Fig. 3.). The area was also equipped with drainage-irrigation ditches, but on deep organic soils in contrary to the first research area. We selected a small part of that system ( $6 \mathrm{ha})$, located between the river and two parallel ditches (Fig. 4.) that constitutes a single, basic quarter out of 22 ones, which form a complete drainage- irrigation scheme altogether.

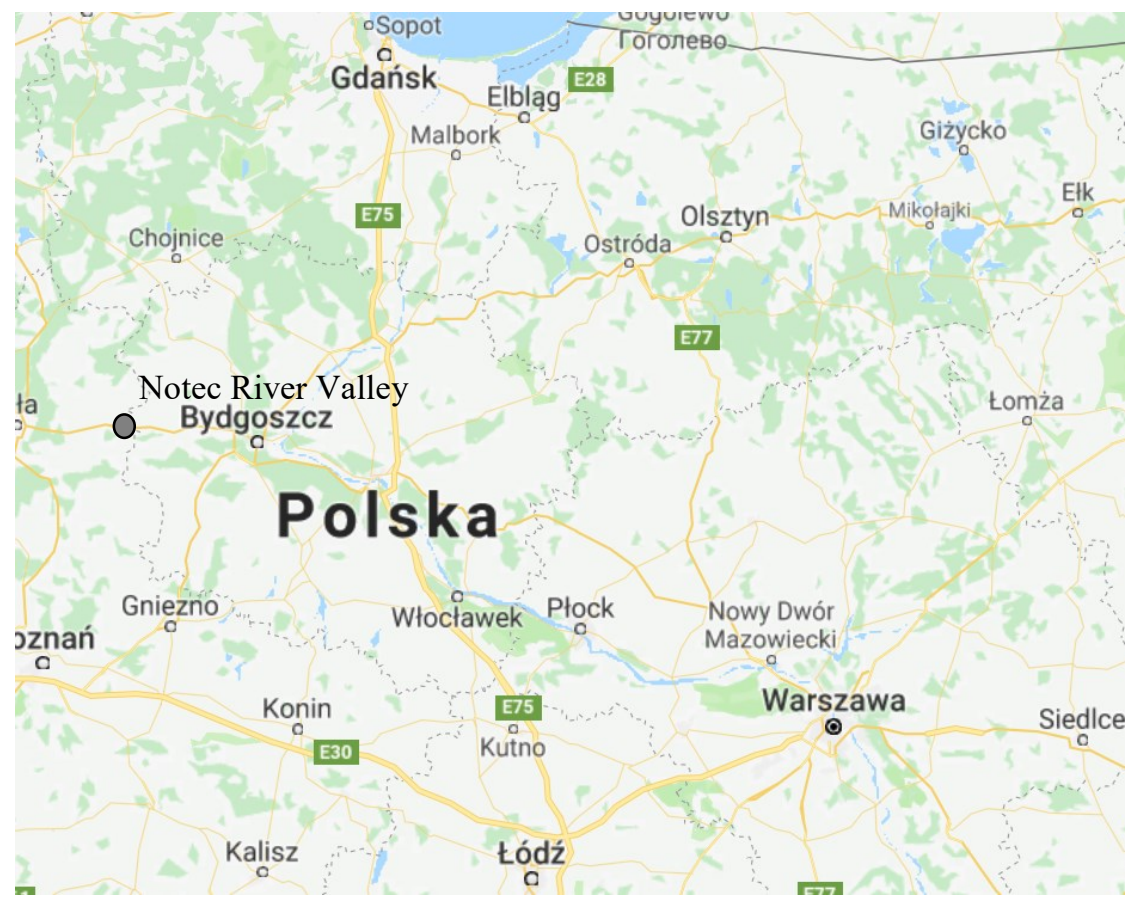

Fig. 3. Location of the second research area- fragments of the Notec River Valley.

That part exhibits a different hydrogeologic setting, with the first layer of peat soils up to 2,5 depth, of a low conductivity, underlain by the layers of sand of a confined water table. So it is directly a two layer ground water system with relatively regular structure of the ditches and canals (Fig. 4.). 


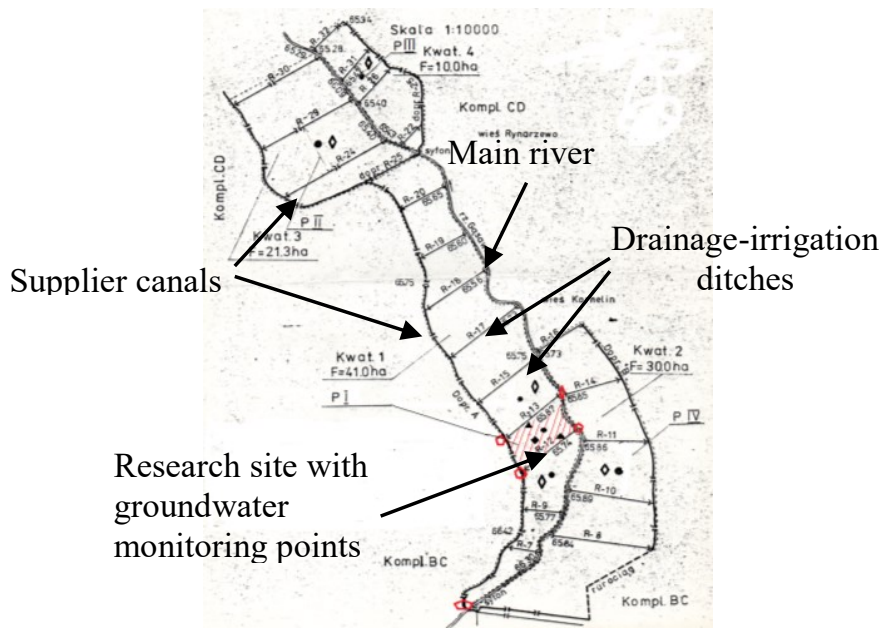

Fig. 4. Drainage - irrigation system of the second research area.

For both research sites we used a common and recognized groundwater flow model Modflow in search of possibilities of a sound and sustainable maintenance of ground water storage. The governing partial- differential equation of this model can be written in the following form [8]:

$$
\frac{d}{d x}\left(T_{x} \frac{d H}{d x}\right)+\frac{d}{d y}\left(T_{y} \frac{d H}{d y}\right)+\frac{d}{d z}\left(T_{y} \frac{d H}{d z}\right)-W=S \frac{d H}{d t}
$$

Where: Tx, Ty, Tz - aquifer transmissivities (m2/s); H- hydraulic head (m); W - inflow or outflow form internal sources or sinks of water $(\mathrm{m} / \mathrm{s})$ (e.g. rainfall, evaporation, channel seepage); S- specific yield (dimensionless); t-time.

In the next stage of analyses, the validation of the models was performed with the use of prior hydrologic information and literature data $[7,9]$. The aim was to prove the reliability of the models to reproduce the ground water table position with the assumed set of parameters. Their input values, especially the conductivities of the sand and peat layers being relatively sensitive ones, but also external inflows or water tables (boundary conditions), precipitation and evapotranspiration etc. produced a reasonable match between observed and modelled groundwater heads (Fig. 5. and Fig. 6.). The first model - that is for the Southern Całowanie Peatland showed an acceptable accuracy $(\mathrm{R} 2=0,76 ; \mathrm{SD}=0,18 \mathrm{~m}$.) while the second one (part of the Noteć basin system) was considered to be of good quality $(\mathrm{R} 2=0,90 ; \mathrm{SD}=0,05 \mathrm{~m}$.).

The stage of model validation was followed by the adoption of criteria to provide for managers' role in the maintenance of a certain environmental status of the analysed areas. It has been still the subject of controversy, and usually requires expert brainstorming, as a wide range of criteria or indicators is too relative [7, 9]. Many of them may be attributed to a general socio-economical and also environmental descriptive view of valley ecosystems. We attempted to evaluate so-called environmental order, basing first of all on freshwater resources indexes and biodiversity maintenance, similar to the approach used in national, statistical yearbooks. From a variety of available evaluation criteria we distinguished the change in groundwater storage within the areas as the first, analysed indicator. The second one was the required groundwater table position, resulting from the prospective soil moisture complex $[7,9,10]$ which is more a hydrological indicator, having also reference to the description of land production potential, but also nature status versus water regime. 


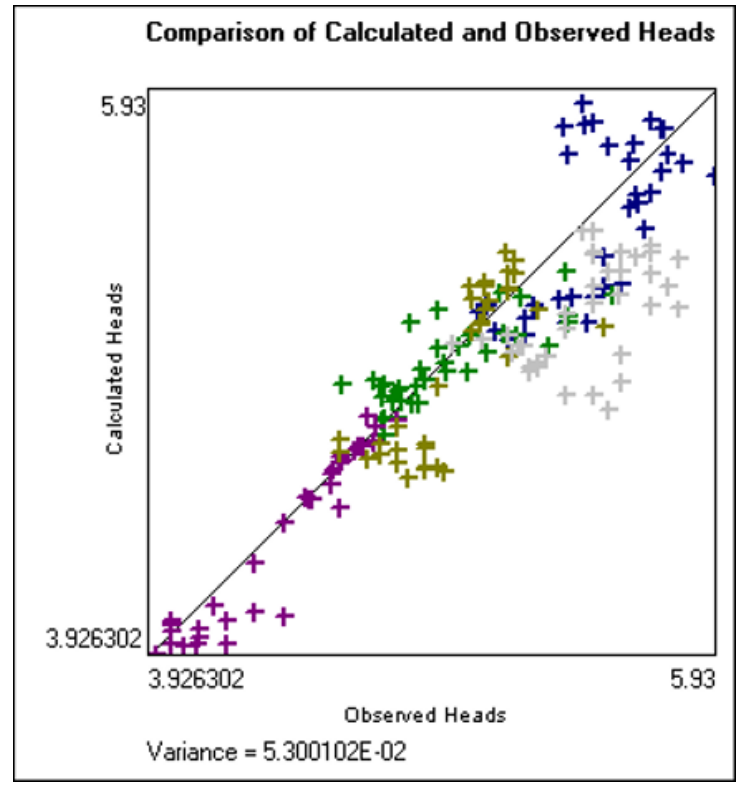

Fig. 5. Scatter diagram for the first model- comparison of observed and calculated heads.

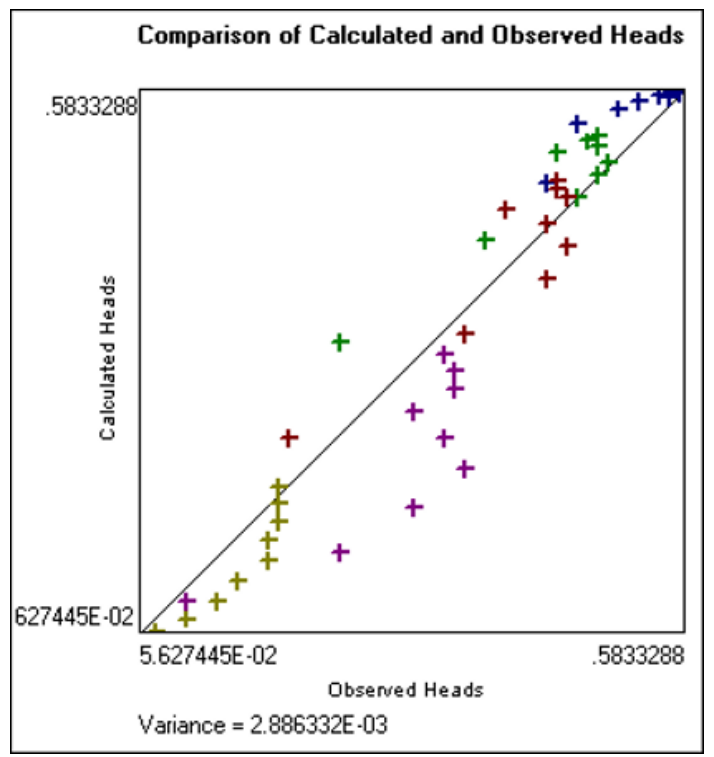

Fig. 6. Scatter diagram for the second model- comparison of observed and calculated heads.

In the last stage of research the models were exploited to evaluate the assumed criteria of a wise either sustainable use of groundwater resources within the analysed areas. The simulations of groundwater flow were executed on experimental data set for hydrological year 2014 (01.11.2013-30.10.2014) on a decade time step, with the input from precipitation, evaporation and mean water levels in channels. 


\section{Results}

The data obtained through modelling made possible to approach sustainable development of two valley ecosystems with emphasis on groundwater - with the first system directly underlain by sandy aquifer, as it was mentioned above, and the second one sitting on organic soils on top of sandy layers. Both systems had in common a limited improvement of existing hydraulic structures over time, that caused the systems to revert to a more natural state. Except for this, the evaluation criteria were also summarized in the previous section, stating that they may depend on variety of factors and are usually the outcome of decisions by experts in their respective fields. Nonetheless, the amount of groundwater coming in and out of the systems was obtained for each month of the year, and the allowable water level decline was as well adopted. For the latter, we used the existing design experience, that divided the soils into moisture categories, so the first research area was assigned the maximum depth to water table of $0,70 \mathrm{~m}$. and the second one equal to $0,85 \mathrm{~m}$. The depth reflected the expected soil properties and targeted area wetness $[7,9]$.

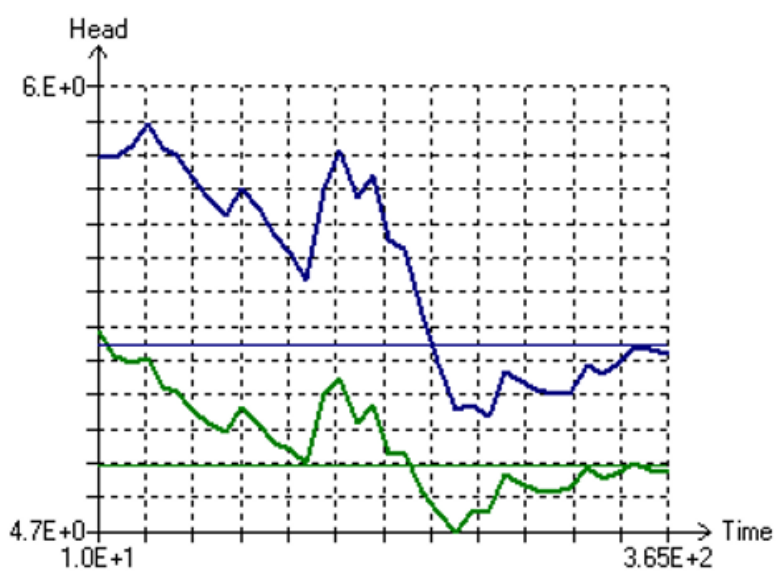

Fig. 7. Groundwater tables versus the allowable decline for two wells within the first area.

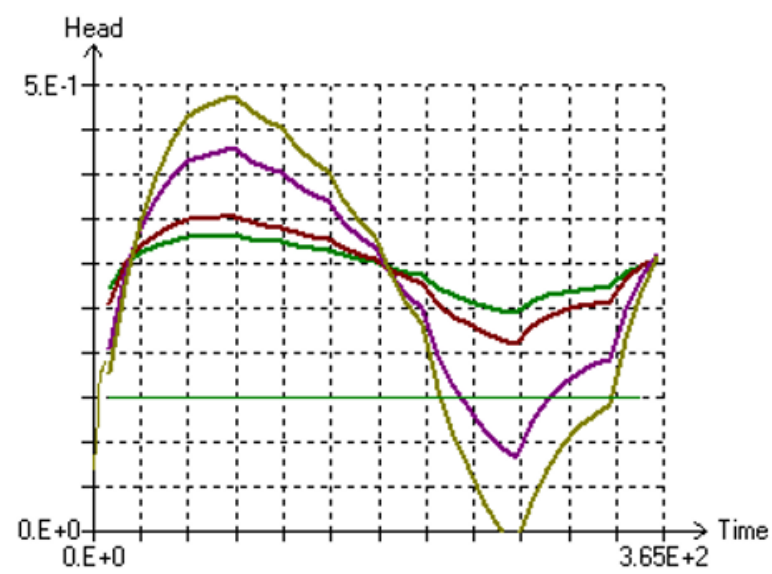

Fig. 8. Groundwater tables versus the allowable decline for fours wells within the second area. 
Groundwater table position was expressed here in a local datum with light lines marking the allowable decline (Fig. 7. and Fig. 8.). For the first, much wider area, the greater differences of altitude were found, so two proper reference levels were marked in Fig. 7. to underpin the maximum acceptable ground water depth. For the second, much smaller area, the differences of ground water heads over the area were not that significant. However, for both areas we could find similar cases, when the lower limit of water table was not met during approximately 4 months (June- September) even if different values of the limit were set due to category of soil water conditions.

The inflows and outflows from the ground water system (Table 1. and Table 2.) revealed 5 months subject to deficit in case of the first analysed area, and already 6 months for the second one. This directly pertains to differences in channel water levels, weather conditions of the analysed period, but also the nature of the soil - mineral types on the first area and organic ones covering the second. Lower inflow values were reached for the second research area, attributable to lower conductivity of organic layers. They were expressed for both areas as unit runoff values in $1 / \mathrm{s} / \mathrm{ha}$.

Table 1. Groundwater budget of the first area $[1 / \mathrm{s} / \mathrm{ha}]$.

\begin{tabular}{|c|c|c|c|c|}
\hline Month & Inflow & Outflow & In-Out & Storage \\
\hline XI & 0,58 & 0,04 & 0,55 & 0,55 \\
\hline XII & 0,06 & 0,12 & $-0,07$ & 0,48 \\
\hline I & 0,06 & 0,01 & 0,04 & 0,52 \\
\hline II & 0,00 & 0,22 & $-0,22$ & 0,31 \\
\hline III & 0,18 & 0,00 & 0,17 & 0,48 \\
\hline IV & 0,00 & 0,33 & $-0,33$ & 0,15 \\
\hline V & 0,37 & 0,00 & 0,37 & 0,52 \\
\hline VI & 0,00 & 0,24 & $-0,24$ & 0,27 \\
\hline VII & 0,47 & 0,01 & 0,46 & 0,73 \\
\hline VIII & 0,08 & 0,01 & 0,07 & 0,81 \\
\hline IX & 0,00 & 0,34 & $-0,34$ & 0,47 \\
\hline X & 0,05 & 0,00 & 0,05 & 0,52 \\
\hline
\end{tabular}

The obtained inflow values generally suggest, that the retrieval towards a primary state, provides for sustainable development of ground water storage in a moderate either limited extent. In case of insufficient water infrastructure maintenance on both areas, the storage of the aquifer is replenished to a similar value by the end of the year, but some months of a negative budget (outflows higher than inflows) are unavoidable. 
Table 2. Groundwater budget of the second area $[1 / \mathrm{s} / \mathrm{ha}]$.

\begin{tabular}{|c|c|c|c|c|}
\hline Month & Inflow & Outflow & In-Out & Storage \\
\hline XI & 0,16 & 0,00 & 0,15 & 0,15 \\
\hline XII & 0,16 & 0,09 & 0,06 & 0,21 \\
\hline I & 0,13 & 0,12 & 0,01 & 0,22 \\
\hline II & 0,09 & 0,10 & $-0,01$ & 0,21 \\
\hline III & 0,05 & 0,07 & $-0,02$ & 0,19 \\
\hline IV & 0,00 & 0,03 & $-0,03$ & 0,16 \\
\hline V & 0,05 & 0,09 & $-0,04$ & 0,13 \\
\hline VI & 0,16 & 0,22 & $-0,06$ & 0,06 \\
\hline VII & 0,21 & 0,25 & $-0,04$ & 0,02 \\
\hline VIII & 0,13 & 0,09 & 0,04 & 0,06 \\
\hline IX & 0,10 & 0,09 & 0,02 & 0,08 \\
\hline X & 0,07 & 0,01 & 0,06 & 0,14 \\
\hline
\end{tabular}

\section{Summary and conclusions}

Actions dedicated to sustainable development of river valleys require evaluation criteria in order to estimate their effectiveness and environmental impacts first of all. For such a broad term, that is namely ,,sustainable development”, an interdisciplinary and a wide range of indicators could be found. In particular, water resources have taken special place here, form the viewpoint of nature protection and wise use of river valley reserves. An attempt to link socioeconomic and environmental aspects is the freshwater resources renewability index, that could be as well used with respect to the maintenance of groundwater storage. Another index, that we proposed to use in reference to sustaining overall ecosystem health, is the desired water table position. In a descriptive sense, it reflects a general habitat type ( soils and moisture status), in other words- a foreseeable quality of the environment. Through a gathered, preliminary data set on groundwater levels and general hydrogeological setting of both areas, as well as assumed criteria, we could note:

- A successful validation of groundwater flow models for two selected valley areas. Having proved the accuracy, a possibility to exploit them for selected sustainable management aspects was opened.

- A multiple of criteria is related with interdisciplinary character of sustainable development of river valleys. Restriction only to hydrologic aspects in groundwater studies resulted in reliable storage estimation of hydrostratigraphic units and adopting desired water table depth.

- Modelled groundwater tables showed a typical course throughout a year for both sites, with spring maximum and summer minimum, and were subject to fall bellow allowable limit from June to September at selected monitoring wells. 
- The storage of groundwater re-established its' value at the end of the year, however, the challenges remain to improve the budget of selected months.

- More natural status of the systems is likely to exist, since little maintenance was performed to hydraulic structures over last decades. At present it is only feasible to keep mean water levels in ditches. This is a limitation to adaptive water management, but the preliminary modelling results suggest, that managers attention to the current situation of the valley ecosystem sustains groundwater storage, but might cause a minor disturbance related with lower water table position in summer.

\section{References}

1. K. Podawca, A. Pawłat-Zawrzykraj, J. Ecol. Eng. 18, 159-167 (2017)

2. A. P. Kozioł, J. Kubrak, Measurements of Turbulence Structure in a Compound Channel. Rivers- Physical, Fluvial and Environmental Processes. Book Series: GeoPlanet-Earth and Planetary Sciences (Springer International Publishing, 2015)

3. A.P. Kozioł, J. Urbański, A. Kiczko, M. Krukowski, P. Siwicki, M. Kalenik., J. Hydrol., Hydromech. 65, 385- 394 (2017)

4. K. Glińska-Lewczuk, P. Burandt, R. Kujawa, S. Kobus, K. Obolewski, J. Dunalska, M. Grabowska, S. Lew, J. Chormański, Water SUI 8, 1-24 (2016)

5. A. Pawłat-Zawrzykraj, M. Brzank, Ann. Warsaw Univ. of Life Sci.-SGGW, Land Reclam. 50, 19-31 (2018)

6. F. Keizera, P.Schot, T. Okruszko, J. Chormański, I. Kardel, M. Wassen, Ecol. Eng. 64, 85-99 (2014)

7. A. Brandyk, G. Majewski, A. Kiczko, A. Boczoń, M. Wróbel, P. PorrettaTomaszewska, Sustainability 8, 12, 1324 (2016)

8. M. McDonald, W. Harbaugh, A modular three-dimensional finite difference groundwater flow model (US Geological Survey, Openfile Report No.6, 1988)

9. A. Brandyk, G. Majewski, Ann. Set The En. Prot. 15, 371-392 (2013)

10. A. Brandyk, Ann. Warsaw Univ. of Life Sci.-SGGW, Land Reclam., 19-31 (2018) 